\title{
Dynamics of Land Cover and Impact on Stream flow in the Modder River Basin of South Africa: Case Study of a Quaternary Catchment
}

\author{
Onalenna Gwate ${ }^{1}$, Yali E. Woyessa ${ }^{2}$, David Wiberg ${ }^{3}$ \\ ${ }^{1}$ Department of Geography and Population Studies, Lupane State University, Zimbabwe \\ ${ }^{2}$ Department of Civil Engineering, Central University of Technology, South Africa \\ ${ }^{3}$ Water Programme, International Institute of Applied Systems Analysis, Laxenburg, Vienna, Austria \\ Email address: \\ onalennag37@gmail.com (O.Gwate)
}

\section{To cite this article:}

Onalenna Gwate, Yali E. Woyessa, David Wiberg. Dynamics of Land Cover and Impact on Stream flow in the Modder River Basin of South Africa: Case Study of a Quaternary Catchment. International Journal of Environmental Protection and Policy. Vol. 3, No. 2, 2015, pp. $31-38$. doi: $10.11648 /$ j.ijepp.20150302.12

\begin{abstract}
Understanding how dynamics in individual land use types influence changes in streamflow is vital. Most hydrological studies are based on paired catchment and modelling approaches. These are data intensive and require a long period of monitoring. To determine the hydrological effects of tropical vegetation conversion over large areas, it is manageable to study the same basin over different time periods. The study analysed changes in historical stream flow patterns with reference to dynamics in land cover in C52A quaternary catchment of South Africa. Landsat images for years 1993, 2004 and 2013 were used for the development of land cover maps. Subsequently, step-change (median point change, Mann-Whitney and Kruskall Willis) and trend detection tests (Spearman's rho and Kindall's tau) were applied to average annual discharge and rainfall data for the catchment between 1984 and 2013.Tukey's honestly significant difference (HSD) test was also used to compare the means. Results revealed that huge land cover changes coincided with significant $(p<0.05)$ changes in streamflow although rainfall remained homogenous over the same period. This suggests that land cover change is intricately coupled to increases in streamflow. In addition, increased runoff is usually accompanied by increased rates of erosion and siltation. To ensure sustainable management of the catchment, therefore, soil and water conservation measures are critical within the broader context of integrated water resources management.
\end{abstract}

Keywords: Change Detection, Land Cover Classification, Landsat Image, Streamflow, Rainfall

\section{Introduction}

Scarcity and misuse of freshwater resources pose serious and growing threats to sustainable development and protection of the environment [1]. The quality and quantity of water heavily impact ecosystem services and human health. River flows are essential for the health of aquatic ecosystems and water supply [2]. Streamflow is also crucial for both ground and surface water resources. Rainfall-runoff relationships within a watershed are the result of the interplay of many factors, but are driven primarily by the interaction of climate, land cover, and soils [3]. Man as a keystone species has been modifying the environment for his own selfish needs. Increasing population necessitates further vegetation clearance to accommodate the farming and settlement needs of the communities which have significantly altered the magnitude and timing of river flows $[4,5,6,7]$.As a result, the health of aquatic ecosystems has declined and some water supplies have become stressed $[8,9,10]$. Therefore, it is imperative to understand the coupling between land use change and the generation of streamflow in a catchment as this influences water balance.

Land use and land cover play a crucial role in driving hydrological processes within watersheds[11].These include changes in water demands e.g. irrigation and urbanization, changes in water supply from altered hydrological processes of infiltration, groundwater recharge and runoff, and changes in water quality from agricultural runoff and suburban development [12]. Sound water resource management is central to the achievement of sustainable development. South Africa has adopted a total catchment approach to the management of water resources. As such the country has 
been divided into water management areas [13]. Land cover change is a primary concern in watershed management as it may also lead to increased flooding, soil degradation and decreased recharge of aquifers. Some studies have suggested that the consequences of land cover change may outweigh those from climate change [14, 8].Understanding the consequences of land-use change for hydrologic processes, and integrating this understanding into the emerging focus on land-change science are major needs for the future [15]. Woyessa et al., focused on the possible impacts on streamflow of scaling up rainwater harvesting techniques by farmers in the C52A catchment of South Africa [16]. However, for a complete understanding of the flow regimes of the system, it is prudent to look at a whole range of land use activities that could possibly pose impacts.

Studies on the effect of land cover changes on streamflow have yielded different and contrasting results $[17,18,19,20]$. Bewket and Sterk noted that such contrasting findings suggest that the impacts of land cover changes on water resource systems vary from place to place depending on sitespecific factors [21]. In addition, [22] believe that changes in a series of hydrological data can occur either gradually or abruptly or in a more complex form. Investigating stream flow patterns with respect to land cover dynamics enables assessment of sustainability of land use systems, because the stream flows are reflections of the ecological state of the entire watershed [21].This may also form a basis for forecasting the likely effects of any potential changes in land cover on water resource systems within this catchment. Therefore, this study analysed changes in annual historical stream flow and rainfall patterns with reference to dynamics in land cover in the C52A catchment in South Africa. The study findings are important in the development of responsive decisions and policy implementations with respect to catchment utilization in South Africa.

\section{Material and Methods}

\subsection{Study Site}

The study site lies between $26^{\circ} 01^{`} 50 \mathrm{E}$ and $27^{\circ} 00^{`} 0 \mathrm{E}$ and $29^{\circ} 0{ }^{\prime} 0 \mathrm{~S}$ and $29^{\circ} 45^{\prime} 0 \mathrm{~S}$. The Modder river originates from the eastern hills of the quaternary catchment C52Abetween Dewetsdorp town and Rustfontein dam located at the outlet of the catchment C52A. The C52A catchment covers about $937 \mathrm{~km}^{2}$ and lies in the semi-arid central South Africa (Figure 1). The soil texture sandy clay loam to sandy clay and is susceptible to crusting. The quaternary catchment $\mathrm{C} 52 \mathrm{~A}$ is located in the undulating and high altitude part of the basin between altitudes of 1400 and $1500 \mathrm{~m}$ above sea level. Mean annual rainfall for the last 30 years was $542 \mathrm{~mm}$ and the maximum mean daily temperature is $29^{\circ} \mathrm{C}$. Vegetation physiognomic type is predominantly savanna grassland.

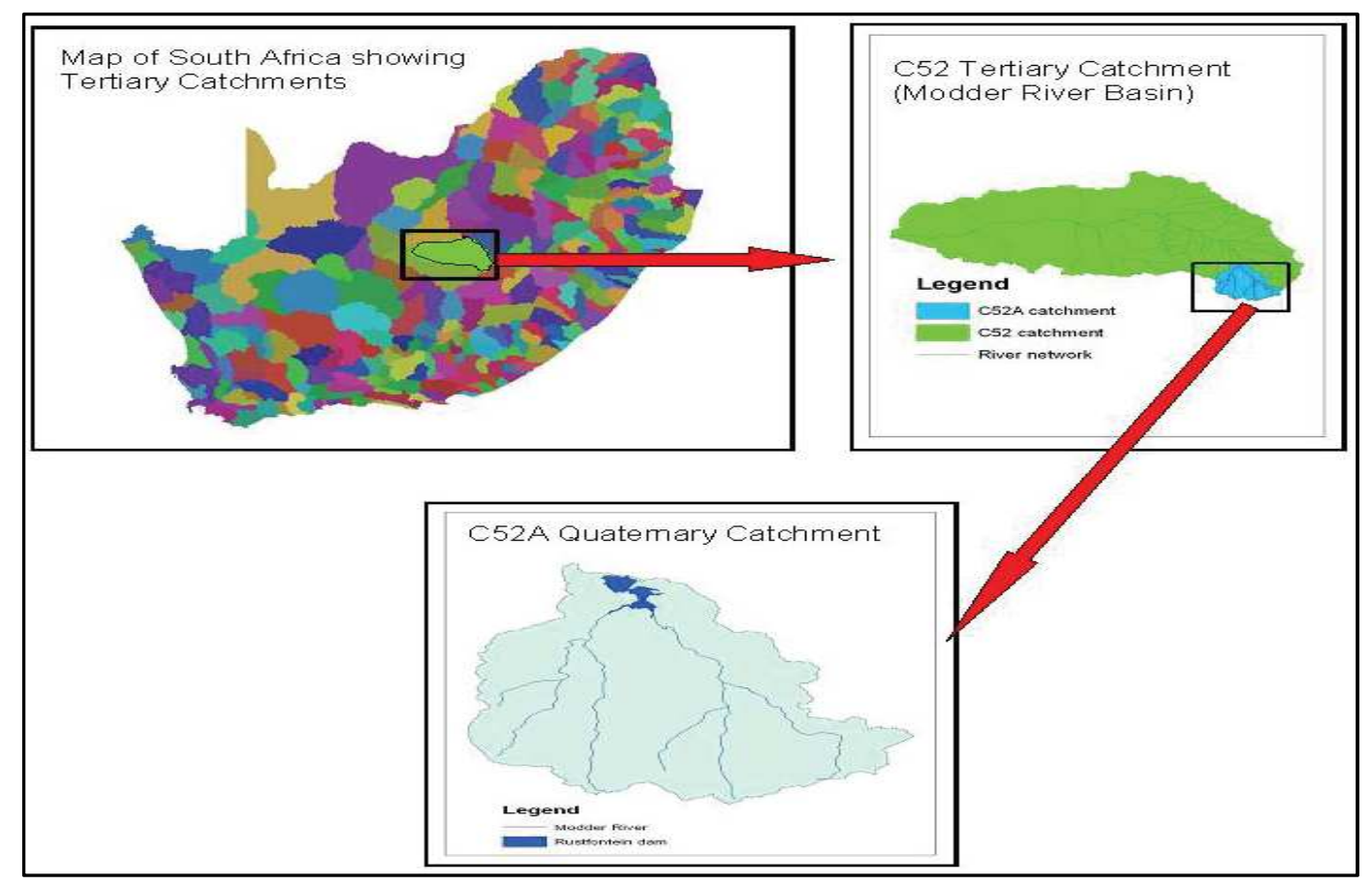

Figure 1. Location of the study area.

\subsection{Method of Analysis}

It has been observed that it is more manageable to study the same basin over different time periods of time rather than adopt a paired catchment approach when determining hydrological effects of tropical vegetation over large areas
[23]. Unlike the conventional methods of the pairedcatchment and modelling approaches which require a long period of monitoring and are data intensive, this study linked breaks or changes in streamflow to land cover dynamics in the catchment to ascertain the coupling between the two. To achieve this, dynamics in land cover between 1993 and 2013 
were assessed using landsat images. Furthermore, average annual streamflow and rainfall data from 1984 to 2013 were subjected to a number of shift and trend detection methods. To this end, classified land cover maps for 1993, 2004 and 2013 were generated for the catchment. Throughout the text, significant difference means that $\mathrm{p}<0.05$ for means comparison.

\section{Statistical shift detection methods applied}

\section{Test for step change}

Rainfall and streamflow data were divided into three periods (1984-1993, 1994-2003 and 2004-2013), taking into consideration the availability of land cover maps The Median change, Kruskal-Wallisand the Mann -Whitney tests were used to detect any changes in the distribution of discharge and rainfall over the years. It is important to use more than one change detection method when dealing with hydrological data in order to ascertain the change [22].The median test compares medians across groups. These are essentially rankbased non parametric tests $[23,22]$.

Test for trend

The Kindall's tauand Spearman's rhotests were applied to establish the presence of any trend in the data. These are nonparametric tests and particularly useful for eliminating influence of extreme or "outlier" values in hydrological data as well as for avoiding the requirements of normal distribution [24]. It should be noted that outliers are common in most hydrological data series. Two tailed test of significance for the correlation between time and hydrological data (discharge and rainfall) was performed.

Analysis of Variance (ANOVA)

Finally, ANOVA was computed to confirm changes in streamflow and rainfall patterns. As such to test for the homogeneity of variances, Levene's test was used. Subsequently, equal variances were assumed and post hoc Tukey's HSD test was applied to enable multiple comparisons of means across sub periods.

\subsection{Land Cover Data and Image Analysis}

The materials used in the study include Landsat TM, ETM and Landsat 8 satellite images for 1993, and 2004 and 2013. GIS and remote sensing software that were used include ArcGIS version ${ }^{\circledR} 10, \operatorname{ArcView}{ }^{\circledR} 3.2$ and ENVI ${ }^{\circledR} 4.3$ All the data were downloaded into the workstation for analysis using the GIS software. Image analysis was done using ENVI® 4.3 software as shown in Figure 2.

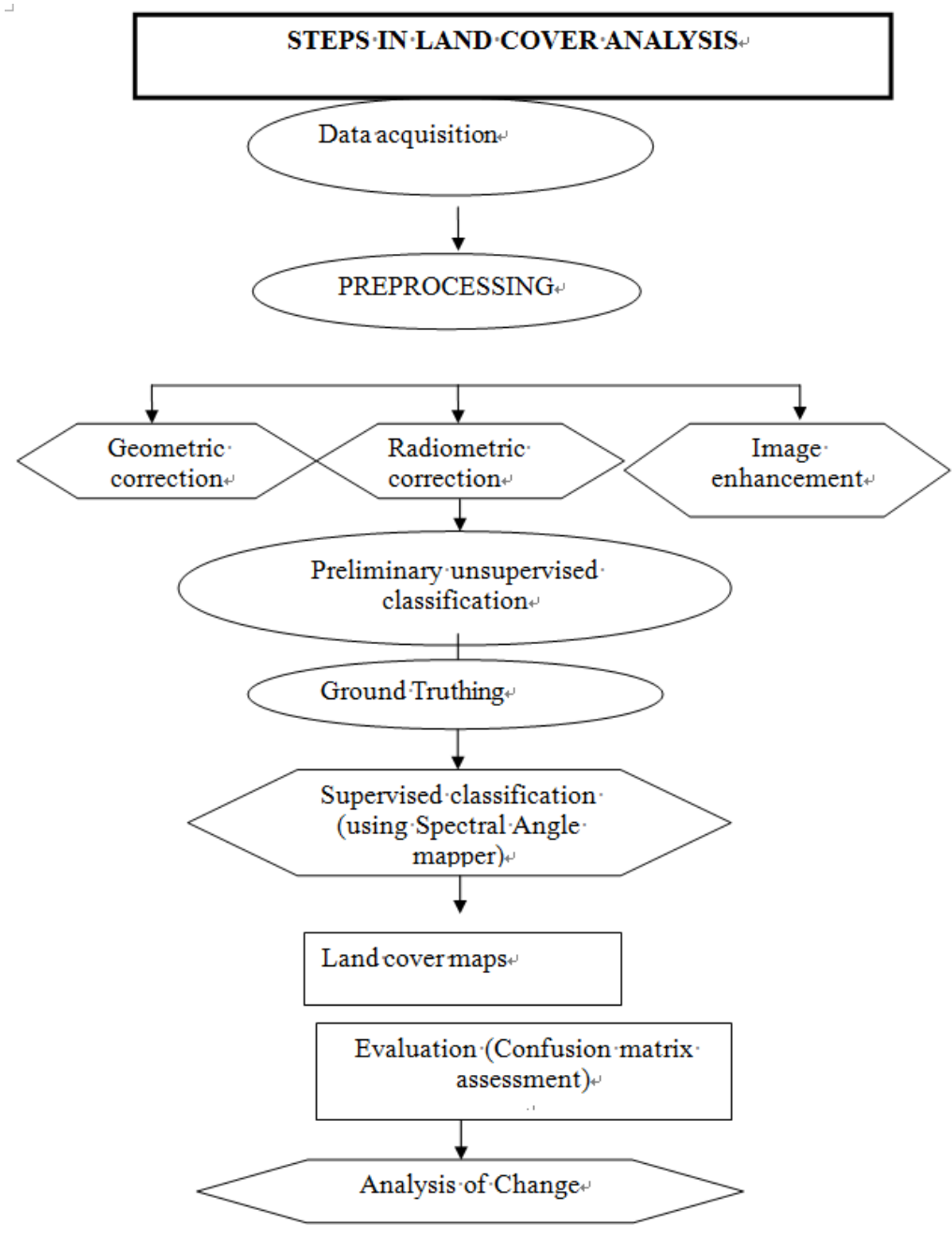

Figure 2. Steps in vegetation analysis. 


\subsubsection{Image Acquisition}

A series of Landsat TM/ETM+ and Landsat 8 images (path 170 row 080) covering the watershed were acquired from NASA portal (GLOVIS). The images were selected for cloud free days during April, May, and June for the years 1993-0318, 2004-06-04, and 2013-04-26. The acquired images were georeferenced and co-registered to one another to allow time line analysis.

\subsubsection{Image Enhancement}

Image enhancement techniques used were contrast stretching at $2.5 \%$, and false colour composites to facilitate the identification of features. The near infrared composite was combined with visible bands (band combination NIR, Red, Green) to produce a false colour composite. Vegetation in the Near Infra-red (NIR) band was highly reflective due to chlorophyll pigment and false colour composite vividly showed vegetation in various shades of red. Built up areas were displayed in blue in the false colour composites while soil colours varied from dark to light brown. Deep red hues indicated broad leaf healthier vegetation while lighter reds signified grasslands or sparse vegetation. Water appeared dark and black depending on depth and clarity, due to absorption of energy in the visible red and NIR bands. False colour composites helped in differentiating water, soil and vegetated areas.

\subsubsection{Normalization}

Most sensors including LANDSAT record reflected electromagnetic radiation by earth features in the form of Digital Numbers (DN). These pose difficulties when comparing multi-temporal images because of differences in sun angle, sensor angle and flight height among other reasons. This problem was circumvented by changing DN values to radiance and then radiance to reflectance, a process called normalization. The following formula was used:

Digital Numbers to Radiance

$$
\operatorname{rad}=\frac{\text { LMAX-LMIN }}{255 * \text { DN }+ \text { LMIN }}
$$

Radiance to reflectance:

$$
\rho p=\frac{\pi * \mathrm{~L} \lambda * \mathrm{~d} 2}{\operatorname{ESUN} \lambda * \operatorname{COS}(\Theta \mathrm{s})}
$$

where:

$\rho \mathrm{p}=$ planetary reflectance,

$\mathrm{L}_{\lambda}=$ spectral radiance at sensor's aperture,

ESUN $_{\lambda}=$ band dependant mean solar exo-atmospheric irradiance,

$\Theta \mathrm{s}=$ solar zenith angle, and

$\mathrm{d}=$ earth-sun distance, in astronomical units

\subsection{Image Analysis}

The images were classified based on four techniques, namely unsupervised K-means, supervised Spectral Angle Mapper (SAM) and visual interpretation.

\subsubsection{K-Means}

$\mathrm{K}$-means is a form of unsupervised classification technique which calculates initial class means evenly distributed in the data space. It then iteratively clusters the pixels into the nearest class using a minimum distance technique. All pixels were classified to the nearest class. It generated a general view of the area, creating a classified image with many clusters that aided in training site selection.

\subsubsection{Spectral Angle Mapper (SAM)}

The Spectral Angle Mapper (SAM) is a physically-based spectral classification that uses an n-dimensional angle to match pixels to reference spectra. It worked by determining the spectral similarity between two spectra, calculating the angle between the spectra, treating them as vectors in a space with dimensionality equal to the number of bands [25]. This technique was used on calibrated reflectance data and was more effective because it was relatively insensitive to illumination and albedo effects compared to other methods like maximum likelihood and minimum distance methods. The end member spectra were collected from false colour images through Region of Interest (ROI) average spectra. The spectra for different land cover classes were compared to typical spectra of known land features for the purpose of separating ambiguity features.

\subsubsection{Visual Analysis}

After the SAM analysis, visual aids were employed for further feature identity based on the features' site, location, arrangement and their shape. Land cover maps were produced for all the satellite image dates and the earlier date image was compared against the later date image in order to establish percentage changes. Image subtraction was done for each class to assess whether there were positive or negative changes on identified corresponding land cover classes.

\subsubsection{Accuracy Assessment of Supervised Classification}

The standard method of Confusion Matrix was used to assess classification accuracy for each image date by comparing classification results with ground truth region of interest (ROIs). The methods of accuracy assessment used included the Kappa statistic and Google Earth. The Kappa statistic is a statistical method of assessing the accuracy that took into account the chance of random agreement. Average accuracy of classification was $78 \%, 80$ and $93 \%$ for 1993 , 2004 and 2013 images respectively.

\subsection{Streamflow and Rainfall Data}

Stream flow data was obtained from the Department of Water Affairs and rainfall data was obtained from the South Africa Weather Services websites. 


\section{Results and Discussion}

\subsection{Land Cover Changes}

Great land transformations have taken place within the catchment during the selected period. Figure 3 and Table 1 show results of land cover classification of C52A quaternary catchment for 1993, 2004 and 2013.

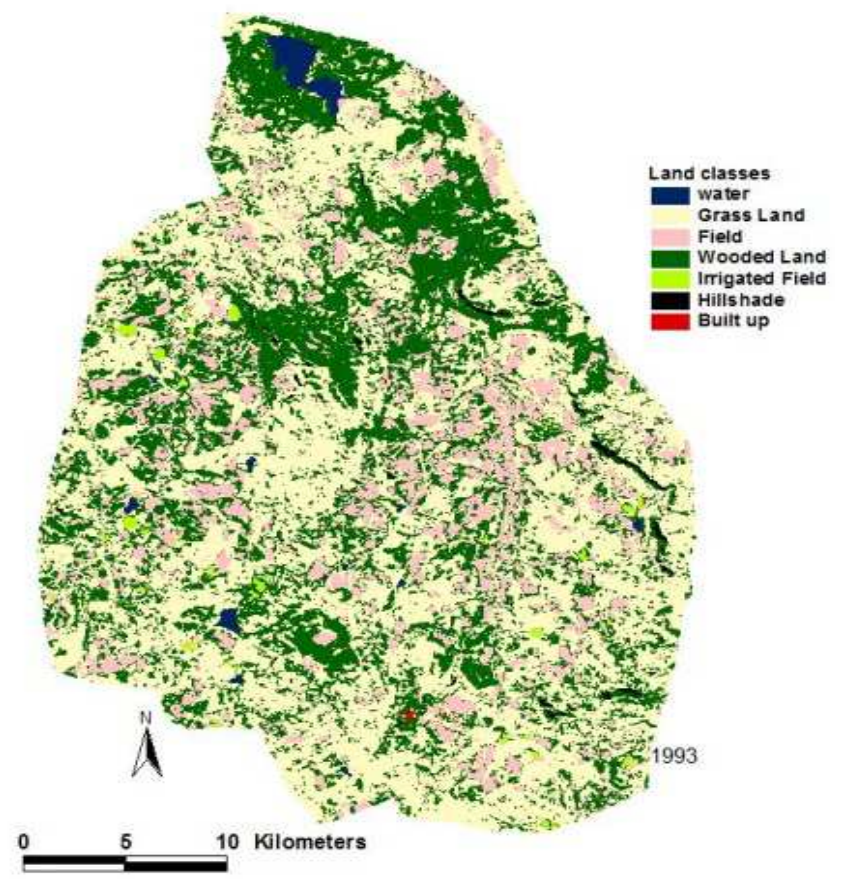

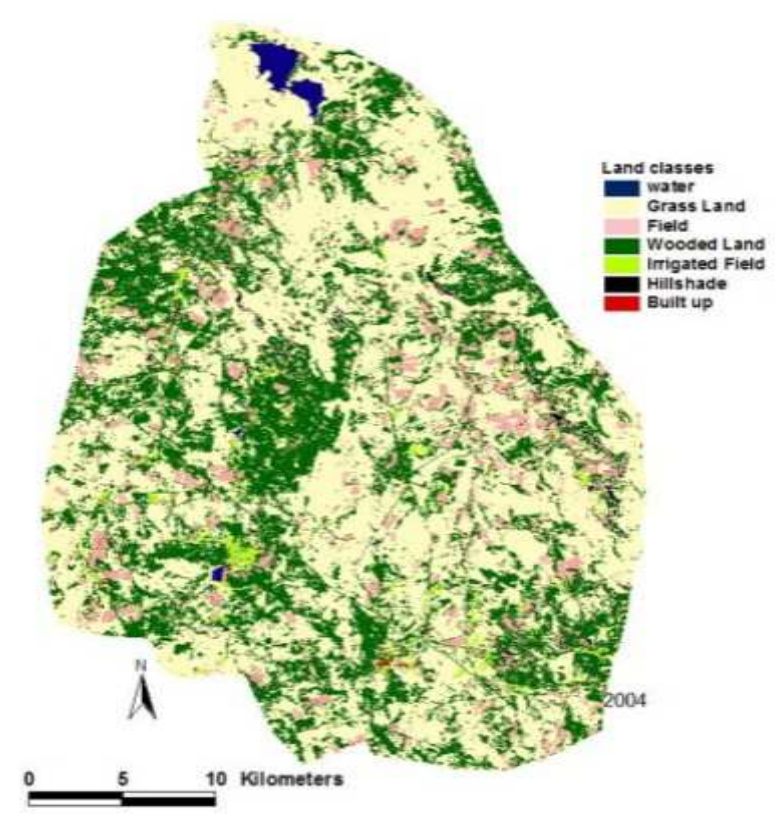

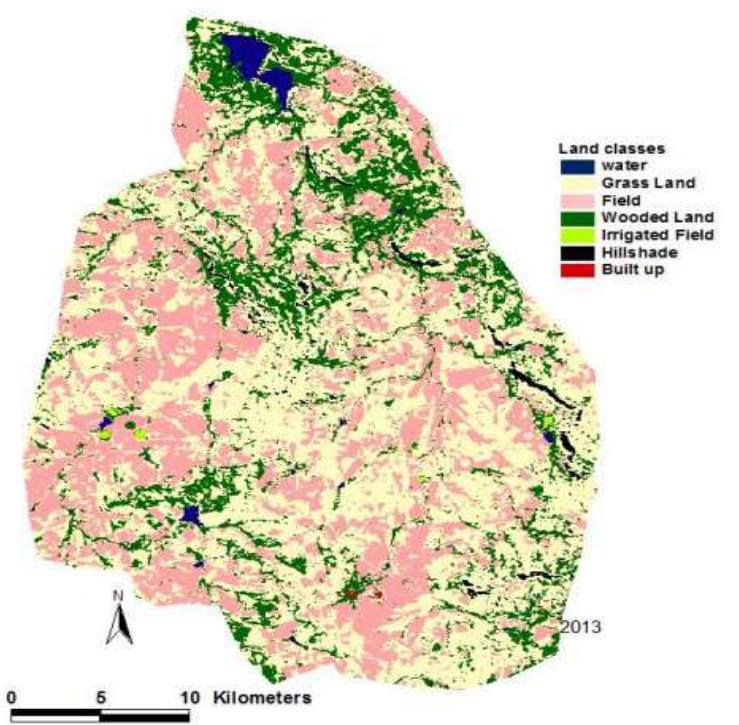

Figure 3. Land cover maps of C52A quaternary catchment for 1993, 2004 and 2013.

Table 1. Land cover changes between 1993 and 2013 in C52A quaternary catchment.

\begin{tabular}{llllll}
\hline Land cover & \%age cover & \%age cover & \%age cover & \%age changes & \%age change \\
\hline & 1993 & 2004 & 2013 & $1993-2004$ & $2004-2013$ \\
Water & 0.95 & 0.89 & 0.99 & -6.7 & -7.3 \\
Grassland & 57 & 54.6 & 49.3 & 14.9 & 9.8 \\
Cultivated area & 15 & 16.6 & 31.8 & 202 & -89 \\
Irrigated field & 0.6 & 1.8 & 0.18 & -1.6 & -35 \\
Wooded land & 25.8 & 25.4 & 16.5 & -40 & 200 \\
Hill shade & 0.5 & 0.3 & 0.9 & 100 & 47 \\
Built up & 0.2 & 0.4 & 0.6 & & \\
Total & 100 & 100 & 100 & & \\
\hline
\end{tabular}

In 1993 most of the land was occupied by grasslands $(57 \%)$, wooded land $(26 \%)$ and cultivated area covered about $15 \%$ of the total area. The irrigated land, built up area and water surface contributed $0.6 \%, 0.2 \%$ and $1 \%$ respectively to the total land cover. Between 1993 and 2004, water and grassland covers decreased by about $6.7 \%$ and $4.3 \%$ respectively. Wooded land slightly decreased by $1.6 \%$ owing to human encroachment. The area occupied by irrigated fields increased by $202 \%$ and the built up area increased by $100 \%$ (Table 1). The cultivated area also increased by about 
$15 \%$. The decrease in grassland cover suggests that other land use options such as cultivation were encroaching into grasslands. By 2004 grassland continued to dominate land cover at $55 \%$ of the total area and declined by about $10 \%$ to contribute $49 \%$ of total catchment coverage in 2013 . The wooded area covered about $25 \%$ in 2004 , declining by about $35 \%$ in 2013 . The cultivated area occupied about $32 \%$ of the total watershed in 2004 and declined by $92 \%$ to contribute $15 \%$ of total area of the catchment in 2013.

\subsection{Change Detection}

\subsubsection{Step-Change Detection}

The results from the Median change point test/ Pettit's test for change reveal that the medians of discharge are not the same across the categories $(p=0.006)$. This suggests a shift in stream flow between 1984 and 2013. Mann-Whitney test revealed that streamflow was not significantly different between the first period (1984-1993) and the second period (1994-2003); but statistically different $(p=0.004)$ between the second period and the third period (2004-2013). The stream flow pattern was also significantly different $(\mathrm{p}=$ 0.003 ) when the first and third periods were compared. The Kruskal-Wallis test also confirmed that the distribution of streamflow across these three sub-periods was not the same $(p=0.003)$ and the mean has been increasing over the selected periods (Figure 4). The three tests above were also applied to rainfall data over the same periods and the differences were statistically insignificant.

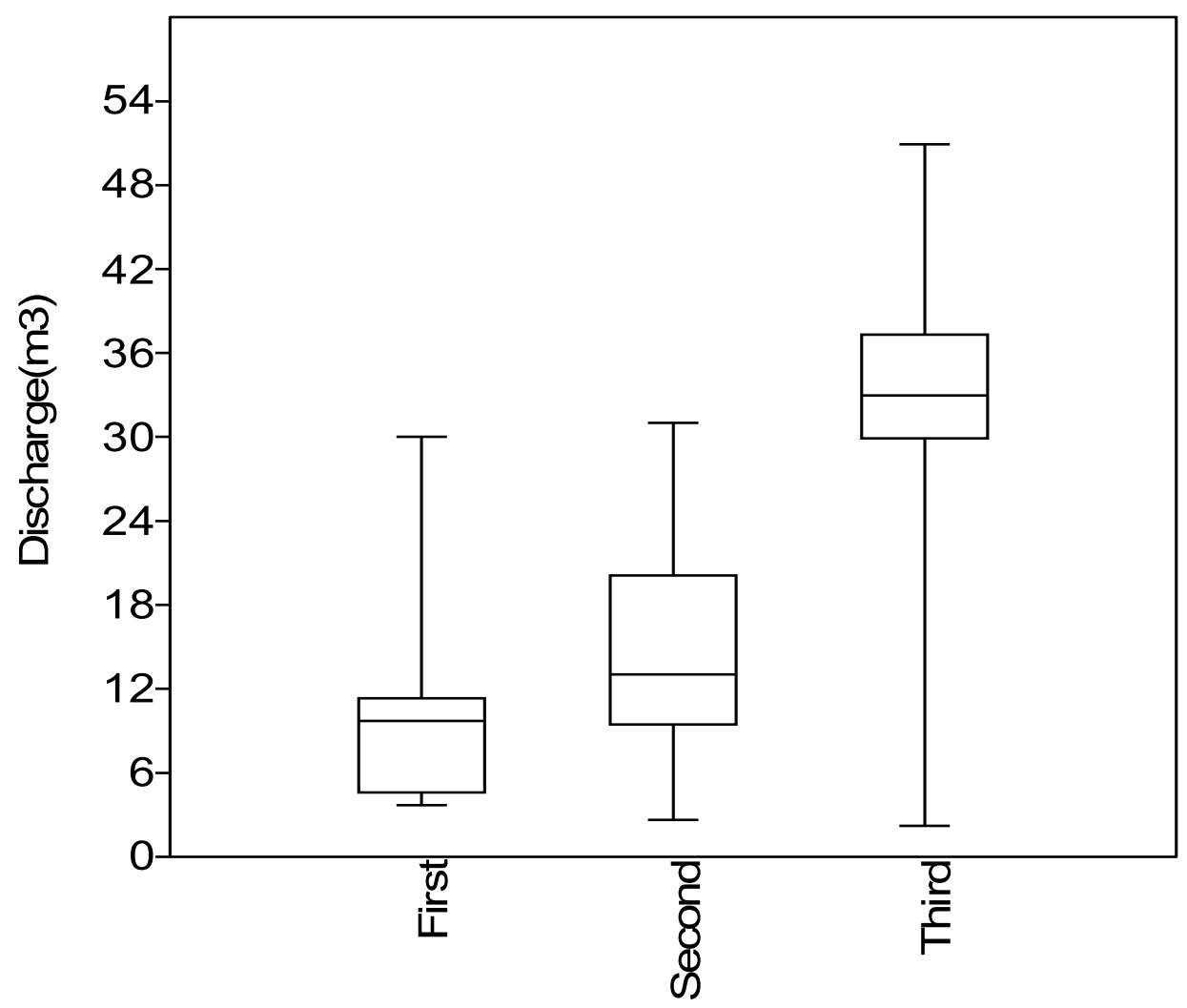

Figure 4. Box plot showing changes in discharge over the first (1984-1993, second (1994-2003) and third periods (2004-2013).

\subsubsection{Trend Detection}

Two trend detection tests in the form of the f Spearman's rho and Kendall's tau were applied to both discharge and rainfall data. The null hypothesis that there is no change in the mean of the data overtime is rejected since results revealed that there was a significant difference $(\mathrm{p}=$ 0.000001 ), suggesting that streamflow is either increasing or decreasing. Figure 4 confirms that mean discharge has been increasing progressively. However, the null hypothesis with respect to rainfall was accepted suggesting that the rainfall was homogenous over these time period.

The Levene test of the homogeneity of variance revealed that the variances were homogenous. Subsequently, the post hoc Tukey's HSD test was performed assuming equal variances.. Results confirmed that the means of the first and second periods were not significantly different $(p=0.74)$ while those of the first and third were significantly different $(p=0.00001)$. The second and third were also significantly different $(\mathrm{p}=0.002)$.

\subsection{Impacts of Land Use Change on Hydrologic Response}

Results suggest that land use has greatly changed in the catchment and rainfall has remained essentially homogenous over the selected period. The observed changes in streamflow 
are to a large extent, not related to climate variability or climate change. The changes in land use coincided with shifts in streamflow patterns. For example during the first period, statistical tests could not detect significant changes in streamflow probably due to smaller land transformations that took place. During this period, cultivated area increased by $14.9 \%$ while grasslands and woodlands decreased by 4.3 and $1.6 \%$ respectively. These land use changes did not result in significant changes in streamflow and this was not surprising because, paired catchment experiments have shown that changes in annual water yield from forest cover reductions of less than $30 \%$ of the catchment could not be detected by streamflow measurement [26]. However, between the second and third period, statistical tests highlighted significant changes and these were accompanied by huge land cover changes. Cultivation increased by about $92 \%$ while wooded land decreased by about $35 \%$ and the grasslands decreased by about $9.8 \%$. Therefore, the increase in streamflow is consistent with common knowledge on the prospective role of tropical forests, that reducing forest cover in forested catchments increases the water yield from the catchment with the majority of the increase occurring in the base flow component [21]. It is also consistent with results from paired catcthment studies[27, 17, 28, 29, 30, 31] that reduction in forest cover increased water yield.Also the area covered by the built up area grew by about $47 \%$ providing ample opportunities for runoff generation because of hard surfaces.

\section{Conclusions}

The contribution of land cover change to streamflow was evaluated by analyzing historical land cover dynamics with reference to streamflow and rainfall patterns. Results suggest that land cover change is one of the major factors influencing streamflow in the C52A catchment. Increase in streamflow coincided with dramatic changes in land cover within the catchment. Management of land use change will be vital for streamflow generation. Future decisions on land use in the catchment will be vital in determining the flow regime and ultimately the water balance in the catchment. Water balance at a catchment level is important since it informs water resource allocation for different user groups including the environment. The increase in streamflow over time suggests that there is increased runoff, usually accompanied by increased rates of erosion and siltation. It can also be discerned from the results that long-term monitoring of land use changes is important for determining trends in hydrology. This information is also important for the development of decision support tools for catchment farmers and managers and to inform policy. In order to ensure sustainable management of the catchment, soil and water conservation measures will be critical within the broader context of integrated water resources management.

\section{Acknowledgements}

We thank the SA YSSP for giving us the opportunity to be part of the 2014 program and for providing the requisite logistics.

\section{References}

[1] ICWE, The Dublin Statement and report of the conference. International Conference on Water and the Environment: Development issues for the 21st century. 26-31 January, Dublin, Ireland (1992).

[2] P.V. Caldwell, G. Sun, S.G, McNulty, E.C. Cohen, M. Myers, Impacts of impervious cover, water withdrawals, and climate change on river flows in the Conterminous US. Hydrological Earth System. Science Discussion 9 (2012) 4263 - 4304.

[3] M. Hernandez, SN.MillerC.D. Goodrich F.B.Goff, W.G. Kepner, C.M. Edmonds, J.K. Bruce, Modeling runoff response to land cover and rainfall spatial variability in semi-arid watersheds.Environmental Monitoringand Assessment64 (2000) 285 - 298.

[4] R.B. Jackson, S.R. Carpenter, C.N.Dahm, D.M. McKnight., R. J. Naiman, S.L. Postel, S.W. Running, Water in a changing world.Ecological applications11 (2001) 1027-1045.

[5] N.L. Poff, J.D. Olden, D.M. Merritt, D.M. Pepin, Homogenization of regional river dynamics by dams and global biodiversity implications, Proceedings of the National Academy of Sciences, USA, 104 (2007) 5732- 5737.

[6] S. Piao, P. Friedlingstein, P.Ciasis, N. de Noblet-Ducoudre, D Labata, S.Zaehle, Changes in climate and land use have a larger direct impact than rising $\mathrm{CO} 2$ on global river 25 runoff trends, Proceedings of the National Academy of Sciences, USA 104 (2007), 15242-15247.

[7] D. Gerten, S. Rost, W. von Blo, W. Lucht, Causes of change in 20th century global river discharge, Geophysical Research Letters., 35(2008)L20405 doi:10.1029/2008GL035258.

[8] C.J. Vörösmarty, P. Green, J. Salisbury, R.B. Lammers, Global water resources: vulnerability from climate change and population growth. Science 289 (2000) $284-288$.

[9] J. Alcamo, T. Henrichs, T. Ro"sch., World water in 2025 global modelling and scenario analysis for the World Commission on Water for the 21st Century. Kassel World Water Series 2, Center for Environmental Systems Research, University of Kassel, Germany (2000).

[10] D.M. Carlisle, D.M. Wolock, M.R. Meador, Alteration of streamflow magnitudes, and potential ecological consequences: a multiregional assessment, Frontiers in Ecology and Environment 9 (2011) 264-270, doi:10.1890/100053.

[11] D. Gerten, S.Schaphoff, W. Haberlandt, W.Luht, S. Sitch, Terrestrial vegetation and water balance-hydrological evaluation of a dynamic global vegetation model.Journal of Hydrology. 286(2004) 249-270

[12] R. DeFries, K.N.Eshleman, Land-use change and hydrologic processes: a major focus for the future, Hydrological Processes Journal 18(2004) $2183-2186$.

[13] Department for Water Affairs and Forestry (DWAF),National Water Resource Strategy - First Edition: September 2004. Government of South Africa 
[14] O.E. Sala, F.S. Chapin, J.J. Armesto, E. Berlow, J. Bloomfield, R. Dirzo, E. Huber-Sanwald, L.F.Huenneke, R.B. Jackson, A. Kinzig, R.Leemans, D.M. Lodge, H.A. Mooney, M. Oesterheld, N.L.Poff, M.T. Sykes, B.M. Walker, M.Walker, D.H. Wall, Biodiversity:global biodiversity scenarios for the year 2100. Science 287 (2000) $1770-1774$.

[15] D.P. Turner, W.D. Ritts, W.B. Cohen, S.T. Gower, M. Zhao, S.W. Running, S.C. Wofsy, S.Urbanski, A.L. Dunn, J.W. Munger, Scaling gross primary production (GPP) over boreal and deciduous forest landscapes in support of MODIS GPP product validation. Remote Sensing of Environment, 88 (2003) $25-270$.

[16] Y.E. Woyessa, E. Pretorius, P.S. van Heerden, M. Hensley, L.D. van Rensburg, Impact of land use on river basin water balance: a case study of the Modder river basin, South Africa, Colombo, Sri Lanka: Comprehensive Assessment Secretariat. Comprehensive Assessment Research Report 12 (2006).

[17] J.M. Bosch, J.D. Hewlett, A review of catchment experiments to determine the effect of vegetation changes on water yield and evapotranspiration. Journal of Hydrology 55(1/4)( 1982) $3-23$.

[18] D.F. Scott, R.E. Smith, Preliminary empirical models to predict reductions in total and low flows resulting from afforestation. Water SA 23 (2) (1997) 135-140.

[19] W. K.B. Elkaduwa, R. Sakthivadivel, Use of historical data as a decision support tool in watershed management: A case study of the Upper Nilwala basin in SriLanka. Research Report 26. Colombo, Sri Lanka: International Water Management Institute (1998).

[20] J.K. Lørup, J.C.Refsgaard, D.Mazvimavi, Assessing the effect of land use change on catchment runoff by combined use of statistical tests and hydrological modelling: case studies from Zimbabwe. Journal of Hydrology 205 (1998) 147 - 163.

[21] W. Bewket, G. Sterk, Dynamics in land cover and its effect on stream flow in the Chemoga watershed, Blue Nile basin, Ethiopia, Journal of Hydrological Processes.19(2005) 445 458 .
[22] Z.W. Kundzewicz, A. J. Robson, Change detection in hydrological records - a review of the methodology / Revue méthodologique de la détection de changements dans les chroniques hydrologiques.Hydrological Sciences Journal49(1)( (2004)) 7 - 19. doi:10.1623/hysj.49.1.7.53993

[23] M. Costa, A. Botta, A.J. Cardile, Effects of large scale changes in land cover on the discharge of the Tocantins river, Southeastern Amazon.Journal of Hydrology 283 (2003), 206 217.

[24] A.N. Pettitt, A non-parametric approach to the change point problem. Applied Statistics 28(1979) 126 - 135

[25] Y. Lin, X. Wei, The impact of large-scale forest harvesting on hydrology in the Willow watershed of Central British Columbia .Journal of Hydrol0gy 359(1-2) (2008) 141-149. doi:10.1016/j.jhydrol.2008.06.023

[26] ENVI EX User's Guide, December, 2009 Edition, ITT Visual Information Solutions.

[27] A.E.Brown, L. Zhang, T.A. McMahon, A.W. Western, R.A.Vertessy,A review of paired catchment studies for determining changes in water yield resulting from alterations in vegetation. Journal of Hydrology 310(1-4) (2005) 28-61. doi:10.1016/j.jhydrol.2004.12.010

[28] A.R Hibbert, Forest Treatment effects on water yield, Reprint from Proceedings of International Symposium on Forest Hydrology, Pennyslavia State University 1965 (1967) 527 543.

[29] F. Gallart, P. Llorens, Catchment management under environmental change: impact of land cover change on water resources. Water International, 28 (3) (2003) 334 - 340.

[30] W. Xiaohu G. Sun, S. Liu, H. Jiang, G. Zhou, L. Dai, The Forest-Streamflow Relationship in China: A 40 year Retrospect. Journal of the American Water Resources Association 44 (5) (2008) 1076 - 1085.

[31] G. Zhou, X. Wei, X. Chen, P. Zhou, Liu, G. Sun, D.F. Scott, S. Zhou, L. Han, Y. Su, Global pattern for the effect of climate and land cover on water yield. Nature Communications 6 (2015) 5918. 